\title{
A general and atom-efficient continuous-flow approach to prepare amines, amides and imines via reactive $\mathbf{N}$-chloramines
}

\author{
Katherine E. Jolley ${ }^{1}$, Michael R. Chapman ${ }^{1}$ and A. John Blacker ${ }^{*} 1,2$
}

\author{
Full Research Paper \\ Address: \\ ${ }^{1}$ School of Chemistry, Institute of Process Research and \\ Development, University of Leeds, Leeds, LS2 9JT, United Kingdom \\ and ${ }^{2}$ School of Chemical and Process Engineering, University of \\ Leeds, Leeds, LS2 9JT, United Kingdom \\ Email: \\ A. John Blacker ${ }^{*}$ - j.blacker@leeds.ac.uk \\ * Corresponding author \\ Keywords: \\ continuous flow; CSTR; $N$-chloramine; synthetic methods; telescoping
}

Beilstein J. Org. Chem. 2018, 14, 2220-2228.

doi:10.3762/bjoc.14.196

Received: 16 April 2018

Accepted: 10 August 2018

Published: 24 August 2018

This article is part of the Thematic Series "Integrated multistep flow synthesis".

Guest Editor: V. Hessel

(C) 2018 Jolley et al.; licensee Beilstein-Institut.

License and terms: see end of document.

\begin{abstract}
Chloramines are an important class of reagents, providing a convenient source of chlorine or electrophilic nitrogen. However, the instability of these compounds is a problem which makes their isolation and handling difficult. To overcome these hazards, a continuous-flow approach is reported which generates and immediately reacts $N$-chloramines directly, avoiding purification and isolation steps. 2-Chloramines were produced from the reaction of styrenes with $N$-alkyl- $N$-sulfonyl- $N$-chloramines, whilst $N$-alkyl or $N, N$ '-dialkyl- $N$-chloramines reacted with anisaldehyde in the presence of $t-\mathrm{BuO}_{2} \mathrm{H}$ oxidant to afford amides. Primary and secondary imines were produced under continuous conditions from the reaction of $N$-chloramines with base, with one example subsequently reduced under asymmetric conditions to produce a chiral amine in $94 \%$ ee.
\end{abstract}

\section{Introduction}

$\mathrm{N}$-Chloramines are versatile reagents, however, their availability is restricted by their stability, so useful would be in situ methods to produce and use them $[1,2]$. The continuous-flow methodology is useful in this context, enabling control over reaction exotherms and improved measures for containment. To evaluate the use of $N$-chloramines in the laboratory requires multiphase flow methods, and until recently these have been limited by the availability of suitable equipment. Microreactors have been used for mixing biphases and employ either static mixers or shaped chambers and channels that repeatedly split and mix the liquids [3-5]. These rely on flow rates within the mixing zone that are sufficient to overcome phase separation [6]. Actively mixed, multistage and variable residence time $\left(t_{\text {res }}\right)$ continuous stirred tank reactors (CSTRs) allow much 
lower flow rates and therefore longer $t_{\text {res }}$ for slow reactions $[7,8]$. The use of CSTRs to carry out sequential or multistep reactions has been exploited by Ley and others [9-11]. The strategy is useful, since it has the potential to eliminate timeconsuming and costly product isolations. In these systems, the reactants and products are fluids which are contacted with solid-supported reagents that after some time require regeneration, which is not convenient within chemical manufacture.

Chloramine itself is unstable, though has been produced safely at large scale using continuous-flow methods; in fact, chloramine has been used as an intermediate in the manufacture of hydrazine using the Raschig process [12,13]. $N$-Alkyl- $N$-chloramines are equally unstable, yet have only been prepared in batch via reaction of a primary or secondary amine with $\mathrm{Cl}_{2}$ gas, $\mathrm{N}$-chlorosuccinimide, chloramine-T or hypochlorite salts $[14,15]$. Whilst $\mathrm{Cl}_{2}$ gas is atom efficient it is difficult to handle, with associated toxicity, and the acid byproduct which leads to $N$-chloramine hydrolysis [16]. On the other hand, $\mathrm{N}$-chlorosuccinimide or chloramine-T are commonly employed, being commercially available, stable and straightforward to handle, though both exhibit poor atom economy [17-21]. Sodium hypochlorite $(\mathrm{NaOCl})$ solutions are less widely used, yet readily available, economic and provide an atom efficient reagent for $N$-chloramine formation [22-24].

A continuous-flow process for the oxidation of alcohols using $\mathrm{NaOCl}$ as a phase-transfer catalyst was recently reported [25]. We have published a communication that describes the continuous mixing of aqueous $\mathrm{NaOCl}$ and an organic solution of secondary amine, using either a tubular reactor with in-line static mixers or a single stage CSTR [26]. The reactor was selected to provide a $t_{\text {res }}$ for optimal conversion. This was achieved according to reaction kinetics and hydrophobicity of the amine, which affects its partition between phases. Herein, we report improvements to this process and the use of $N$-alkyl- $N$-chloramine in subsequent continuous-flow reactions (Figure 1).

These reagents can be used as electrophilic or radical amination agents in a wide range of reactions [14]. In the present study, we opted to evaluate the addition of $\mathrm{N}$-alkyl- $\mathrm{N}$-chloramines with (a) alkenes to produce amines, (b) aldehydes to give amides, (c) reaction with a base to afford imines. Several alkenes are known to react with $N$-haloamines to form aziridines and other $N$-heterocycles. Typically, the reactions require a catalyst (e.g., $\mathrm{Cu}, \mathrm{I}_{2}$ ) [17,18,27], whilst more active reagents such as chloramine- $\mathrm{T}$ with osmate catalysts have been used to make 1,2-aminoalcohols and diamines [28-33]. Improved methods for the formation of amides remain an important goal for the pharma industry. In this regard, the reaction of $N$-chloramine with aldehydes, $t-\mathrm{BuO}_{2} \mathrm{H}$ and iron or copper catalysts to give secondary and tertiary amides was reported in batch recently $[33,34]$, though safety concerns upon scale-up makes this a useful reaction to translate to flow. Likewise, imines are an important class of compounds and are increasingly used as precursors to optically active amines [35-39]. Whilst normally prepared via a corresponding carbonyl compound, final dehydration can be problematic. The oxidation of a racemic amine and subsequent chiral reduction may offer a valuable alternative if coupled into a sequential flow protocol. There are reports on the formation of imines from $\mathrm{N}$-chloramines using bases (e.g., $\mathrm{NaOMe}, \mathrm{KO} t$-Bu, $\mathrm{NEt}_{3}$ and $\mathrm{NaOH}$ ) [40-45], with one specific study using this technique to racemise and resolve enantiopure tetrahydroquinolines [46,47], and another accessing an intermediate to the drug telaprevir [45]. Our study complements these findings, by supplying a continuous-flow oxidation-reduction sequence which telescopes both $\mathrm{N}$-chloramine and imine intermediates to produce chiral amines.

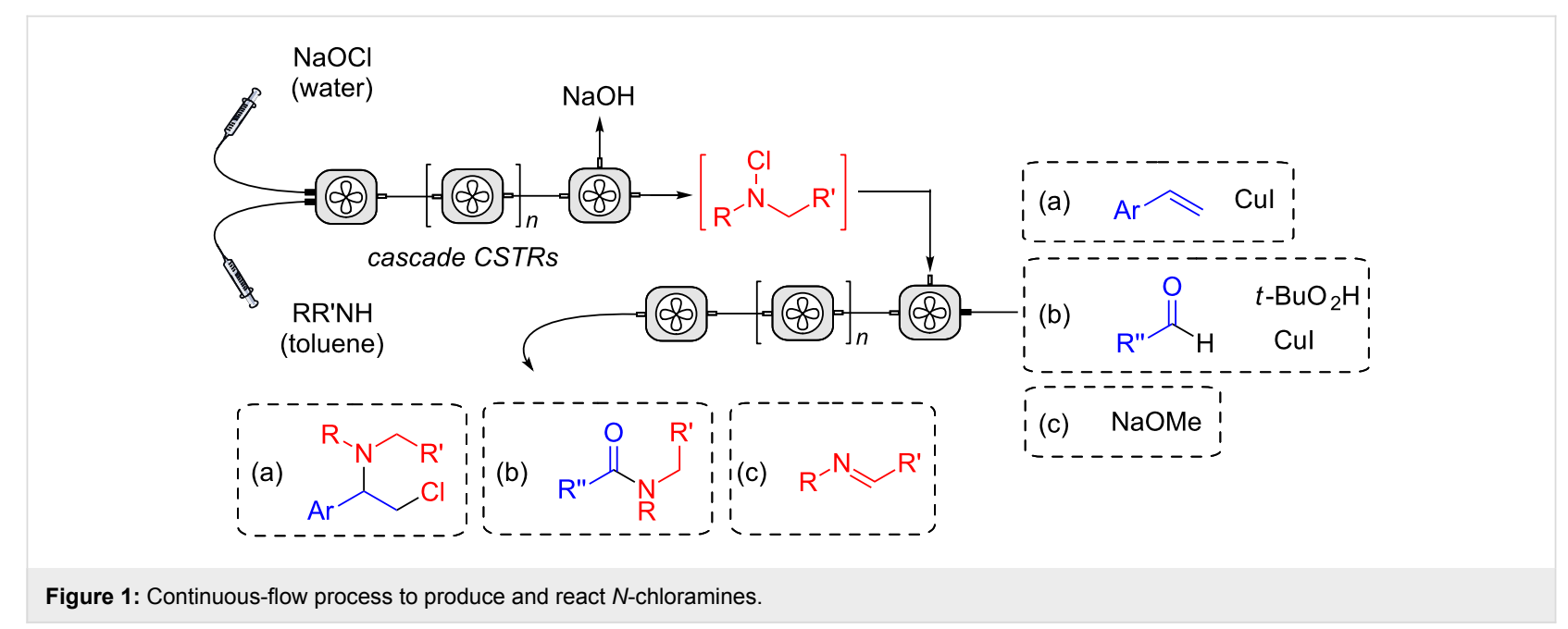




\section{Results and Discussion}

\section{$\mathrm{N}$-Chloramine formation}

$N$-(Di)alkyl- $N$-chloramines have been prepared in continuous organic-aqueous biphasic flow using either static mixers or a single-stage CSTR [26]. The choice of reactor and definition of $t_{\text {res }}$ for this reaction is governed by both the thermodynamic phase partition parameter of reactants and mixing efficiency which control mass transfer between each phase (and thus, reaction rate). We decided to exploit a multi-stage cascade CSTR developed by our group recently [8], which enables efficient mixing over long $t_{\text {res }}$ (Figure 2).

Using a 5-stage variant, various unsymmetrical $N$-chloramines were produced with unprecedented productivities (Table 1).

The rapid nature of this chlorination step makes in situ generation and consumption feasible in flow mode. Comparing Table 1, entries 1 and 3, the 5-stage CSTR, with one fifth the
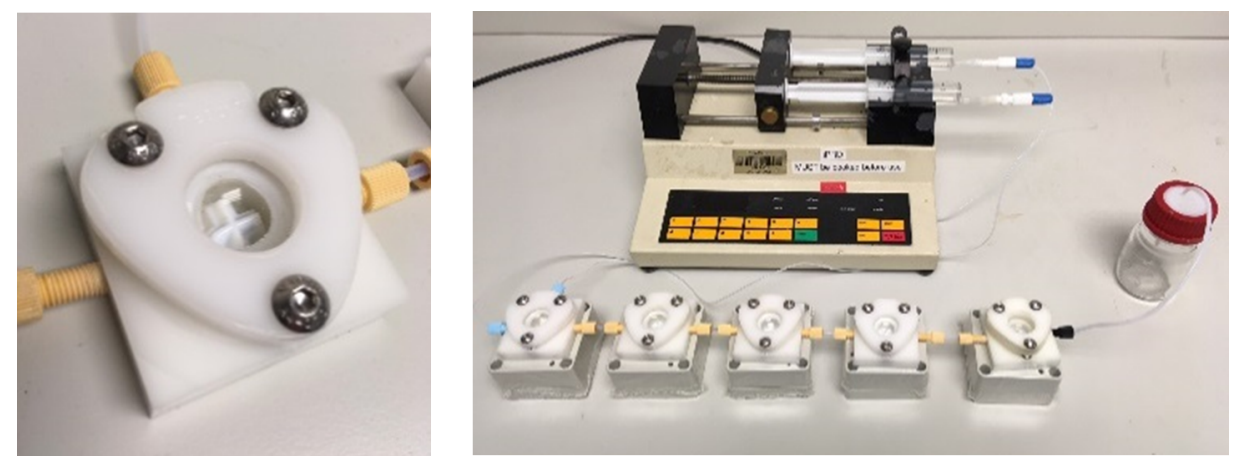

Figure 2: Left: Laboratory scale CSTR developed by our group [8]. Right: 5-stage CSTR configuration using co-feeds of amine in toluene and aqueous $\mathrm{NaOCl}$.

Table 1: Continuous $\mathrm{N}$-chloramine formation.

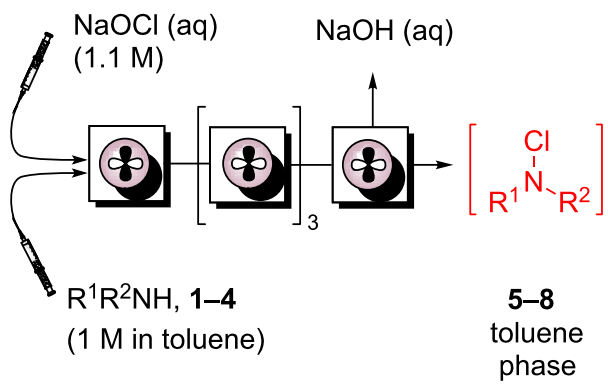

$$
\begin{aligned}
& \text { 1,5: } R^{1}=M e, R^{2}=B n \\
& \text { 2,6: } R^{1}=H, R^{2}=-C H(M e) P h \\
& \text { 3,7: } R^{1}=M e, R^{2}=-C H(M e) P h \\
& \text { 4,8: } R^{1}, R^{2}=-C H(M e)\left(\mathrm{CH}_{2}\right)_{4^{-}}
\end{aligned}
$$

\begin{tabular}{lllllll}
\hline entry & starting material & product & reactor $^{\mathrm{a}}(\mathrm{vol} / \mathrm{mL})$ & $t_{\text {res }}(\min )$ & ${\text { conversion }(\%)^{\mathrm{b}}}$ & productivity $\left(\mathrm{mol} \mathrm{L}^{-1} \mathrm{~h}^{-1}\right)$ \\
\hline 1 & $\mathbf{1}$ & $\mathbf{5}$ & $\operatorname{SM~}(6)$ & 20 & 89 & 1.3 \\
2 & $\mathbf{1}$ & $\mathbf{5}$ & $\operatorname{CSTR}^{\mathrm{c}}(50)$ & 25 & 100 & 1.2 \\
3 & $\mathbf{1}$ & $\mathbf{5}$ & $\operatorname{CSTR}^{\mathrm{d}}(10)$ & 5 & 94 & 5.6 \\
4 & $\mathbf{2}$ & $\mathbf{6}$ & $\operatorname{CSTR}^{\mathrm{d}}(10)$ & 10 & 92 & 2.8 \\
5 & $\mathbf{3}$ & $\mathbf{7}$ & $\operatorname{CSTR}^{\mathrm{d}}(10)$ & 30 & 93 & 0.9 \\
6 & $\mathbf{4}$ & $\mathbf{8}$ & $\operatorname{CSTR}^{\mathrm{d}}(10)$ & 10 & 100 & 3.0 \\
\hline
\end{tabular}

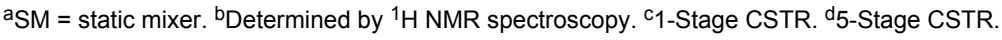


volume of that in Table 1, entry 2, provides a much shorter $t_{\text {res }}$ than the in-line static mixer (SM) with comparable conversion of $N$-benzyl- $N$-methylamine (1) to the $N$-alkyl- $N$-chloramine $\mathbf{5}$ at steady state, representing a productivity value of $5.6 \mathrm{~mol} \mathrm{~L}^{-1} \mathrm{~h}^{-1}$. The same reactor geometry was used to chlorinate primary, secondary acyclic and cyclic amines $2-\mathbf{4}$ in conversions between $92-100 \%$, with productivities ranging between 0.9-3 mol L ${ }^{-1} \mathrm{~h}^{-1}$ (Table 1, entries 4-6). In each case, separation of the product-rich toluene phase avoided $N$-chloramine isolation and allowed direct deployment in further reactions.

\section{Reaction of $N$-chloramine with alkene}

Initially our study tested the reaction of $N$-chloromorpholine (16) to styrene (13) varying $\mathrm{Cu}$ catalyst loading and a range of temperatures. The anti-Markovnikov addition product was observed with $10 \% \mathrm{CuI}$ catalyst loading, at ambient temperature. However, it required 24 hours (see Supporting Information File 1, S1), and this slow reaction prevents sensible translation of the process into continuous flow. Despite trying alternative catalysts or other conditions no improvement was found. Instead, the more electron-poor $N$-chloro- $N$-methyl- $p$-toluenesulfonamide (11) was investigated as substrate. Differential scanning calorimetry (DSC) was used to assess the thermal stability of 11 , which melts at $78{ }^{\circ} \mathrm{C}$ and decomposes between
160-200 ${ }^{\circ} \mathrm{C}$. This profile peaks at $188^{\circ} \mathrm{C}$, corresponding to an enthalpy of decomposition of $-84.7 \mathrm{~kJ} \mathrm{~mol}^{-1}$ (see Supporting Information File 1, S2). A maximum safe operating temperature of $110^{\circ} \mathrm{C}$ was implemented to avoid thermal decomposition and thermal runaway.

The direct reaction of $N$-chloramine 11, or the benzyl-substituted variant $\mathbf{1 2}$, led to a single regioisomer of the amine product in a lower reaction time than the analogous reaction using 16 (15 minutes vs 24 hours in batch mode; Supporting Information File 1, Table S1, entry 2 and Table 2, entries 1-5. The products 14 and 15, prepared in batch, were isolated in 78 and $68 \%$ yield, respectively, and characterized (see Supporting Information File 1, S4). These standards enabled monitoring of the steady-state conversion in continuous flow by ${ }^{1} \mathrm{H}$ NMR.

Following an optimization study, it was found that the $\mathrm{Cu}$ catalyst could be omitted when operating at $100{ }^{\circ} \mathrm{C}$ for 1 hour reaction time in batch, providing quantitative conversion to product (Table 2, entry 4). Conducting the same reaction under an atmosphere of air or in the presence of TEMPO, suppressed all product formation (Table 2, entry 5). Due to the safety concerns of scaling-up such a batch reaction, a heated single-stage CSTR was evaluated to immediately quench the $N$-chloramine. Flowing an aqueous solution of in situ generated 11 or 12 into a

Table 2: Batch vs flow study of reaction of $N$-chloramine with styrene.

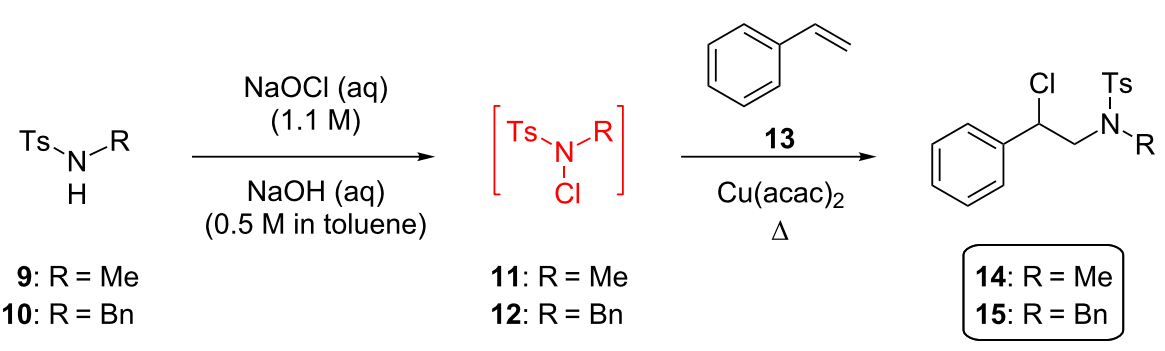

\begin{tabular}{|c|c|c|c|c|c|c|}
\hline entry & mode/substrate & catalyst (mol \%) & temperature $\left({ }^{\circ} \mathrm{C}\right)$ & time $(\min )$ & product & conversion $(\%)^{a}$ \\
\hline 1 & batch/9 & 2 & 100 & 15 & 14 & 62 \\
\hline 2 & batch/9 & 2 & 80 & 15 & 14 & 98 \\
\hline 3 & batch/9 & 2 & rt & 60 & 14 & 50 \\
\hline 4 & batch $/ \mathbf{9}$ & 0 & 100 & 60 & 14 & 100 \\
\hline $5^{b}$ & batch $/ 9$ & 0 & 100 & 60 & 14 & 0 \\
\hline 6 & batch/10 & 2 & 110 & 60 & 15 & 100 \\
\hline $7^{c}$ & CSTR/9 & 0 & 100 & $\begin{array}{l}30 \\
60 \\
75\end{array}$ & 14 & $\begin{array}{l}12 \\
73 \\
76\end{array}$ \\
\hline $8^{c}$ & CSTR/10 & 0 & 100 & $\begin{array}{l}30 \\
60 \\
120\end{array}$ & 15 & $\begin{array}{l}67 \\
77 \\
77 \\
\end{array}$ \\
\hline
\end{tabular}

${ }^{a}$ Conversion measured by ${ }^{1} \mathrm{H}$ NMR spectroscopy. ${ }^{\mathrm{b}}$ Reaction carried out in either air or presence of TEMPO (1 equiv) led to the same result. ${ }^{\mathrm{c}} 1$-Stage CSTR, co-feed with styrene in toluene and substrate in toluene/diglyme 3:1. 
stream of toluene containing styrene (13) enabled the continuous production of alkylated amine products $\mathbf{1 4}$ and $\mathbf{1 5}$ (Table 2, entries 7 and 8 , respectively). In each case the $t_{\text {res }}$ was comparable with batch (reaction of $\mathbf{1 1}=75$ minutes, $\mathbf{1 2}=60$ minutes), with steady-state conversions or 76 and $77 \%$ observed, respectively.

\section{Reaction of $\mathrm{N}$-chloramine with aldehyde}

Reaction of $N$-chloramines with aromatic and aliphatic aldehydes to form amides has been reported by Porcheddu [34]. Under these literature conditions, $\mathrm{FeCl}_{3}$ catalyst $(0.15 \mathrm{~mol} \%)$, $t-\mathrm{BuO}_{2} \mathrm{H}$ oxidant (3.6 equiv) and excess aldehyde 17 (5 equiv) were employed to react with dilute $N$-chloramine $16(0.064 \mathrm{M}$ in $\mathrm{MeCN}$ ), delivering amide $\mathbf{1 8}$ in $77 \%$ conversion and $54 \%$ isolated yield. Our interests were to improve the productivity of this system, by exploiting higher concentrations of $N$-chloramine produced in flow mode $(200 \mathrm{mM})$. Table 3 summarizes a comparative study between batch and continuous flow for this reaction.

Initial tests involving $200 \mathrm{mM}$ substrate concentration afforded amide 18 in $60 \%$ conversion (Table 3, entry 2). Increasing the catalyst loading to $15 \mathrm{~mol} \%$ led to a quantitative conversion of 18 within 1 hour reaction time. Unexpectedly, a control reaction omitting the $\mathrm{FeCl}_{3}$ catalyst resulted in $90 \%$ conversion following a two-hour reaction time (Table 3, entry 4). Removing the $t-\mathrm{BuO}_{2} \mathrm{H}$ oxidant reduced the reaction rate significantly, leading to $10 \%$ conversion under otherwise identical conditions (Table 3 , entry 5), whilst fewer equivalents of aldehyde 17 led to $30 \%$ product formation (Table 3, entry 6). Notably, other oxidants such as $\mathrm{H}_{2} \mathrm{O}_{2}$ and $\mathrm{NaOCl}$ failed to produce any amide product. Likewise, attempts to couple morpholine in place of its $N$-chloro derivative reached only 19\% conversion.

Following the investigation of the batch reaction, it was transferred to a CSTR. Feeding $200 \mathrm{mM} \mathrm{N}$-chloramine to meet a separate solution of aldehyde 17 (5 equiv) and $t-\mathrm{BuO}_{2} \mathrm{H}$ (5 equiv), a $t_{\text {res }}$ of 100 minutes afforded amide $\mathbf{1 8}$ in $70 \%$ conversion at steady state. Under analogous conditions, $\mathrm{FeCl}_{3}(5 \mathrm{~mol} \%)$ was included in the oxidant stream to give 96\% steady-state conversion to $\mathbf{1 8}$ (Figure 3). This data represents productivities of 19 and $26 \mathrm{~g} \mathrm{~L}^{-1} \mathrm{~h}^{-1}$ for the uncatalysed and $\mathrm{FeCl}_{3}$-catalyzed amide formation, respectively (Supporting Information File 1, S4).

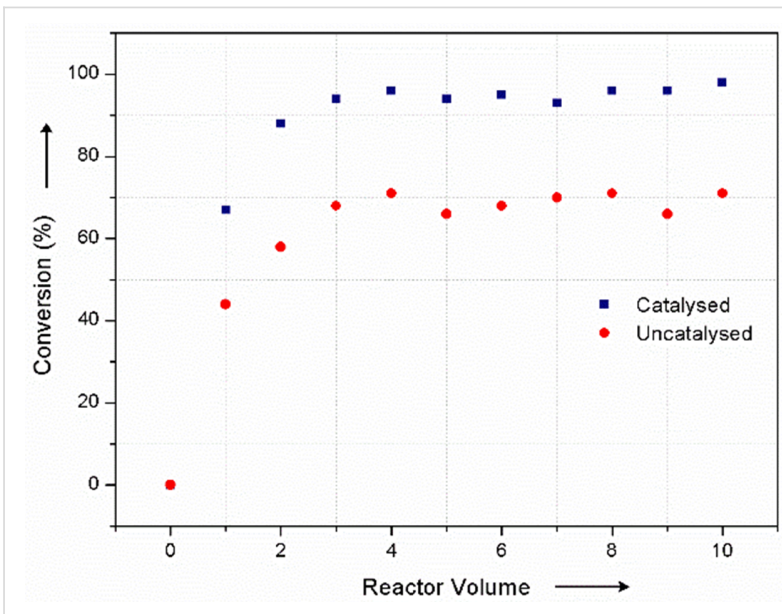

Figure 3: Continuous-flow amide 18 formation using 1-stage CSTR. Blue squares: $\mathrm{FeCl}_{3}$ included; red circles: $\mathrm{FeCl}_{3}$ not included.

Table 3: Batch vs flow study of reaction of $\mathrm{N}$-chloramine with an aldehyde.<smiles>ClN1CCOCC1</smiles>

16, $200 \mathrm{mM}$<smiles>COc1ccc(C=O)cc1</smiles>

17

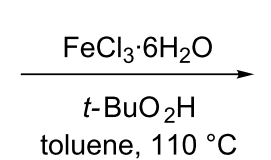

toluene, $110^{\circ} \mathrm{C}$<smiles>COc1ccc(C(=O)N2CCOCC2)cc1</smiles>

18

\begin{tabular}{|c|c|c|c|c|c|}
\hline entry & mode & $\mathrm{FeCl}_{3}(\mathrm{~mol} \%)$ & equiv $17 / t-\mathrm{BuO}_{2} \mathrm{H}$ & time (min) & conversion/yield $(\%)^{a}$ \\
\hline $1^{b}$ & batch & 0.15 & $5 / 3.6$ & 300 & $77 / 54$ \\
\hline $2^{c}$ & batch & 0.15 & $5 / 3.6$ & 300 & 60 \\
\hline 3 & batch & 15 & $5 / 3.6$ & 60 & 100 \\
\hline 4 & batch & 0 & $5 / 3.6$ & 120 & 90 \\
\hline 5 & batch & 15 & $5 / 0$ & 120 & 10 \\
\hline 6 & batch & 0 & $1 / 3.6$ & 120 & 30 \\
\hline 7 & CSTR & 0 & $5 / 5$ & 100 & $70^{d}$ \\
\hline 8 & CSTR & 5 & $5 / 5$ & 100 & $96^{d}$ \\
\hline
\end{tabular}

${ }^{\mathrm{a} C}$ Conversion measured by gas chromatography as the average of three runs. ${ }^{\mathrm{b}}$ Literature conditions quoted as $88 \%[34] .{ }^{\mathrm{C}}[16]=200 \mathrm{mM}$. dConversion recorded at steady state. 


\section{Reaction of $\mathrm{N}$-chloramine with base}

The base-induced dehydrochlorination of $N$-chloramines is a facile route to imines, which may be used for further functionalization. Our study began by examining a host of bases to convert $\mathrm{N}$-chloramine 5 to benzylidene(methyl)amine (19) as a model reaction system (Table 4).

To achieve a complete conversion, $\mathrm{NEt}_{3}$ was required in large excess ( 5 equiv) over 42 hours, which proved unsuitable for continuous flow (Table 4, entry 1). Whilst KOt-Bu and $\mathrm{NaOMe}$ bases allowed rapid imine formation (Table 4, entries 2-6), though their low solubility in $\mathrm{MeOH}$ or toluene would require slurry pumping in flow mode which is undesirable. In addition, the isolation procedure is not straightforward, requiring multiple unit operations. To avoid this, a phase-transfer catalyst (TBAB) was used along with $\mathrm{NaOH}$ (Table 4, entries 7-9). This reagent, in a toluene/water mixture, promoted full conversion to imine 19 (Table 4, entry 8). The separation of the toluene phase provided the imine product, which may be deployed directly in further reactions.

To validate the batch protocol $N$-chloramines 5 and 7 underwent smooth dehydrochlorination to produce imines $\mathbf{1 9}$ and $\mathbf{2 0}$ in 83 and $100 \%$ conversion after 1 hour (Table 5, entries 1 and $2)$. The cyclic $N$-chloramine 8 was converted in batch mode to the corresponding imine $\mathbf{2 1}$, though required 18 hours to reach $84 \%$ conversion (Table 5, entry 3 ). The rapid nature of the imine formation prompted us to investigate a fully continuous protocol to both $\mathrm{N}$-chlorinate and subsequently dehydrochlorinate amines, which would represent a mild and atom-efficient alternative method of amine oxidation. A 5-stage cascade CSTR was employed to link $N$-chloramine generation with basepromoted imine formation. A $1 \mathrm{M}$ stream of $N$-chloramine 5 in toluene was mixed in the first CSTR with separate flows of aqueous $\mathrm{NaOH}$ and TBAB (10 mol \% relative to substrate) and $t_{\text {res }}$ was adjusted by changing the number of subsequent CSTR chambers $(n)$ (Table 5, entry 1$)$. It is noteworthy that attempts to mix $\mathrm{NaOH}$ and $\mathrm{TBAB}$ solutions via a T-piece prior to the mixing chamber were not successful, as a precipitate forms from the mixture leading to reactor blockage. A quantitative conversion of 5 to imine $\mathbf{1 9}$ was realized using the $\mathrm{NaOH} /$ TBAB protocol with a $t_{\text {res }}$ of 2 hours with good productivity $\left(0.25 \mathrm{~mol} \mathrm{~L}^{-1} \mathrm{~h}^{-1}\right.$, Table 5 , entry 1$)$. Under analogous conditions, $N$-chloramine 7 was converted to imine $\mathbf{2 0}$ in $88 \%$ conversion, which could be improved to $99 \%$ conversion by extending $t_{\text {res }}$ to 3 hours (Table 5 , entry 2). However, the same conditions proved only able to convert $19 \%$ of the $N$-chloramine 8 at steady state with $t_{\text {res }}$ of 2 h (Table 5 , entry 3 ). To achieve a higher conversion an impractical $t_{\text {res }}$ would be required if the same batch conditions were used. In this regard, the use of heated CSTRs would be useful to explore.

The formation of both imines $\mathbf{2 0}$ and $\mathbf{2 1}$ are of interest as an asymmetric reduction would give an optically pure amine. To demonstrate this, imine 20, formed in situ, underwent asymmetric-transfer hydrogenation in both batch and flow modes, using $\left[\mathrm{IrCp} * \mathrm{Cl}_{2}\right]_{2}$ as catalyst with the ligand $(R, R)$-TsDPEN, using the hydrogen-donor reagent formic acid/triethylamine (Scheme 1).

Table 4: Batch optimization study of the dehydrochlorination of $\mathrm{N}$-chloramines

\begin{tabular}{|c|c|c|c|c|c|}
\hline entry & base & catalyst & solvent & time $(\mathrm{h})$ & conversion (\%) ${ }^{\mathrm{a}}$ \\
\hline 1 & $\mathrm{NEt}_{3}$ (5 equiv) & none & toluene & 42 & 92 \\
\hline 2 & $\mathrm{KO} t$-Bu (5 equiv) & none & $\mathrm{MeOH}$ & 15 & 90 \\
\hline 3 & $\mathrm{NaOMe}$ (2 equiv) & none & toluene/MeOH 1:1 & 2 & 100 \\
\hline 4 & $\mathrm{NaOMe}$ (10 equiv) & none & toluene/MeOH 1:1 & 1 & 100 \\
\hline 5 & $\mathrm{NaOMe}$ (1 equiv) & none & toluene/MeOH 1:1 & 1 & 47 \\
\hline 6 & $\mathrm{NaOMe}$ (5 equiv) & none & toluene & 1 & 100 \\
\hline 7 & $\mathrm{NaOH} 25 \%$ aq & $\mathrm{TBAB}^{\mathrm{b}}$ & toluene/water $1: 1$ & 1 & 83 \\
\hline 8 & $\mathrm{NaOH} 25 \%$ aq & $\mathrm{TBAB}^{\mathrm{b}}$ & toluene/water $1: 1$ & 3 & 100 \\
\hline 9 & $\mathrm{NaOH} 40 \%$ aq & $\mathrm{TBAB}^{\mathrm{b}}$ & toluene/water 1:1 & 1 & 50 \\
\hline 10 & $\mathrm{NaOH} 25 \%$ aq & none & toluene/MeOH (1\%) & 19 & 0 \\
\hline 11 & $\mathrm{NaOH} 25 \%$ aq & none & toluene/MeOH (20\%) & 19 & 0 \\
\hline
\end{tabular}

a Measured by ${ }^{1} \mathrm{H}$ NMR spectroscopy. ${ }^{\text {b }}$ Reaction temperature $=60^{\circ} \mathrm{C}$. 
Table 5: Batch vs flow study of the dehydrochlorination step.

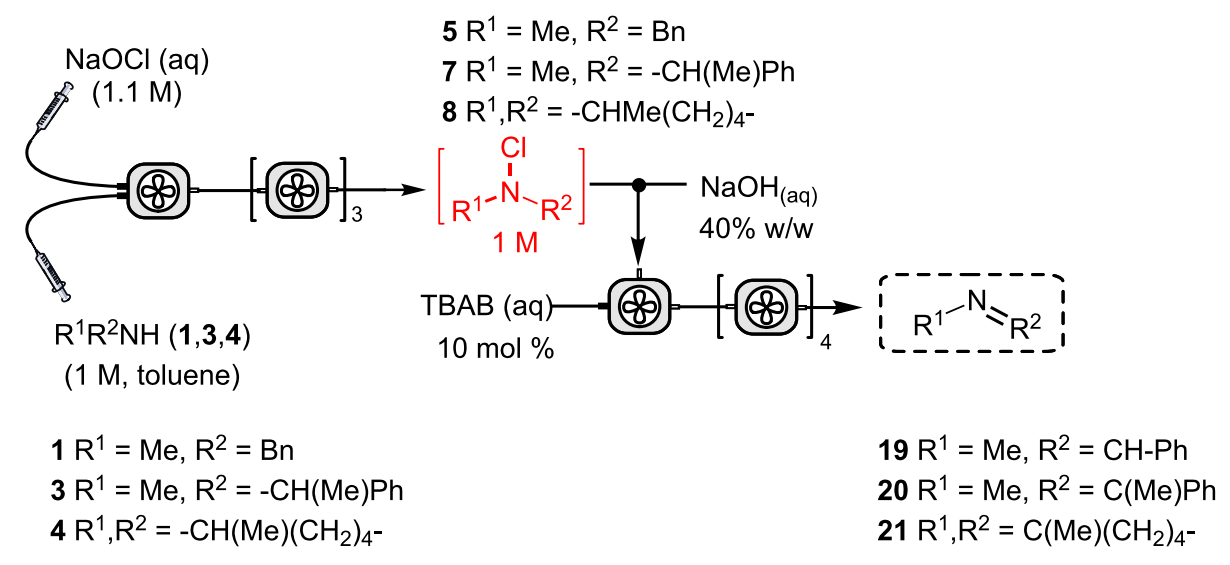

\begin{tabular}{|c|c|c|c|c|}
\hline entry & product & mode & $t_{\text {res }}(\mathrm{h})$ & conversion $(\%)^{a}$ \\
\hline 1 & 19 & $\begin{array}{l}\text { batch } \\
\text { flow }\end{array}$ & $\begin{array}{l}1 \\
2\end{array}$ & $\begin{array}{l}83 \\
100\end{array}$ \\
\hline 2 & 20 & $\begin{array}{l}\text { batch } \\
\text { flow } \\
\text { flow }\end{array}$ & $\begin{array}{l}1 \\
2 \\
3\end{array}$ & $\begin{array}{l}100 \\
88 \\
99\end{array}$ \\
\hline 3 & 21 & $\begin{array}{l}\text { batch } \\
\text { flow }\end{array}$ & $\begin{array}{l}18 \\
2\end{array}$ & $\begin{array}{l}84 \\
19\end{array}$ \\
\hline
\end{tabular}

aMeasured by ${ }^{1} \mathrm{H}$ NMR spectroscopy.

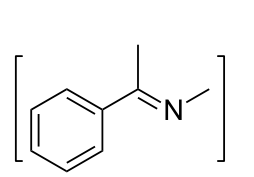

20
$\left[\mathrm{IrCp}{ }^{*} \mathrm{Cl}_{2}\right]_{2}(0.5 \mathrm{~mol} \%)$

$(R, R)$-TsDPEN $(1 \mathrm{~mol} \%)$
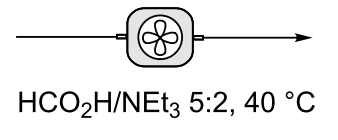

$\begin{aligned} \text { batch } t_{\text {res }} & =120 \mathrm{~min} \\ \text { flow } t_{\text {res }} & =30 \mathrm{~min}\end{aligned}$

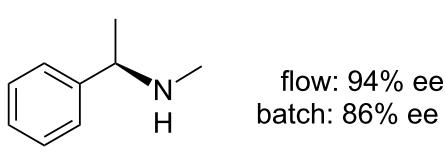

22, $100 \%$ conv

Scheme 1: Continuous-flow transfer hydrogenation of in situ generated imines.

Under batch conditions, a $t_{\text {res }}$ of 120 minutes gave quantitative reduction of the imine, affording the $R$-isomer in $86 \%$ ee. Translating the procedure to continuous flow, a fresh solution of imine 20 and catalyst mixture were pumped into a heated CSTR over a 30-minutes $t_{\text {res }}$, affording chiral amine 22 in 94\% ee with complete conversion. It is unclear why a higher optical activity was seen using continuous flow. However, it is known that $\left[\mathrm{IrCp} * \mathrm{Cl}_{2}\right]_{2}$ can slowly racemise this amine which may be more of a problem in batch with the longer reaction time [48].

\section{Conclusion}

A continuous-flow approach to prepare and handle unstable $\mathrm{N}$-chloramines is reported. The method exploits the superior mixing of a CSTR compared with classical batch, to enable fast $N$-chlorination of amines under biphasic conditions. By virtue of a flowing solution, the in situ generated chloramines may be transferred directly into new reaction media, with examples of (i) addition to an alkene to form a new $\mathrm{C}-\mathrm{N}$ and $\mathrm{C}-\mathrm{Cl}$ bond, (ii) reaction with aldehyde to produce amides, and (iii) dehy- 
drochlorination with a base to afford imines reported within our study. Of these examples, the latter was further explored by immediate asymmetric-transfer hydrogenation of an in situ formed imine under continuous-flow conditions, as a potentially productive route to chiral amines.

\section{Supporting Information}

\section{Supporting Information File 1}

Details of reactor assembly, $\mathrm{NaOCl}$ titration and NMR spectra.

[https://www.beilstein-journals.org/bjoc/content/ supplementary/1860-5397-14-196-S1.pdf]

\section{Acknowledgements}

The research for this work has received funding from the Innovative Medicines Initiative joint undertaking project Chem 21 under grant agreement $\mathrm{n}^{\circ} 115360$, resources of which are composed of financial contribution from the European Union's Seventh Framework Programme (FP7/2007-2013) and EFPIA companies in kind contribution.

\section{ORCID ${ }^{\circledR}$ iDs}

Katherine E. Jolley - https://orcid.org/0000-0001-6223-9808

A. John Blacker - https://orcid.org/0000-0003-4898-2712

\section{References}

1. Urben, P. In Bretherick's Handbook of Reactive Chemical Hazards, 7th ed.; Bretherick, L., Ed.; Academic Press: Oxford, 2007; pp 15-20.

2. Antelo, J. M.; Arce, F.; Parajo, M. J. Phys. Org. Chem. 1996, 9, 447-454.

doi:10.1002/(SICI)1099-1395(199607)9:7<447::AID-POC778>3.0.CO;2 $-X$

3. Wiles, C.; Watts, P. Eur. J. Org. Chem. 2008, 1655-1671. doi:10.1002/ejoc.200701041

4. Zhang, Y.; Born, S. C.; Jensen, K. F. Org. Process Res. Dev. 2014, 18, 1476-1481. doi:10.1021/op500158h

5. Wiles, C.; Watts, P. Green Chem. 2012, 14, 38-54. doi:10.1039/C1GC16022B

6. Nagy, K. D.; Shen, B.; Jamison, T. F.; Jensen, K. F. Org. Process Res. Dev. 2012, 16, 976-981. doi:10.1021/op200349f

7. Mo, Y.; Jensen, K. F. React. Chem. Eng. 2016, 1, 501-507. doi:10.1039/C6RE00132G

8. Chapman, M. R.; Kwan, M. H. T.; King, G.; Jolley, K. E.; Hussain, M.; Hussain, S.; Salama, I. E.; González Niño, C.; Thompson, L. A.; Bayana, M. E.; Clayton, A. D.; Nguyen, B. N.; Turner, N. J.; Kapur, N.; Blacker, A. J. Org. Process Res. Dev. 2017, 21, 1294-1301. doi:10.1021/acs.oprd.7b00173

9. Pastre, J. C.; Browne, D. L.; Ley, S. V. Chem. Soc. Rev. 2013, 42, 8849-8869. doi:10.1039/c3cs60246j

10. Ley, S. V. Chem. Rec. 2012, 12, 378-390. doi:10.1002/tcr.201100041

11. Wegner, J. C.; Ceylan, S.; Kirschning, A. Adv. Synth. Catal. 2012, 354, 17-57. doi:10.1002/adsc.201100584
12. Worley, S. D.; Wojtowicz, J. A. Kirk-Othmer Encyclopedia of Chemical Technology; John Wiley \& Sons Inc., 2000.

13. Rothgery, E. F. Kirk-Othmer Encyclopedia of Chemical Technology; John Wiley \& Sons Inc., 2000.

14. Kovacic, P.; Lowery, M. K.; Field, K. W. Chem. Rev. 1970, 70, 639-665. doi:10.1021/cr60268a002

15. Wille, U. In Science of Synthesis; Enders, D.; Schaumann, E., Eds.; Thieme: Stuttgart, 2009; Vol. 40b, pp 846-847.

16. Seppelt, K.; Sundermeyer, W. Z. Naturforsch., B: Anorg. Chem., Org. Chem., Biochem., Biophys., Bio I. 1969, 24, 774-775. doi:10.1515/znb-1969-0622

17. Lyalin, B. V.; Petrosyan, V. A. Russ. J. Electrochem. 2000, 36, 164-169. doi:10.1007/bf02756901

18. Heuger, G.; Kalsow, S.; Göttlich, R. Eur. J. Org. Chem. 2002, 1848-1854. doi:10.1002/1099-0690(200206)2002:11<1848::AID-EJOC1848>3.0.C $\mathrm{O} ; 2-\mathrm{V}$

19. Grandl, J.; Sakr, E.; Kotzyba-Hibert, F.; Krieger, F.; Bertrand, S.; Bertrand, D.; Vogel, H.; Goeldner, M.; Hovius, R. Angew. Chem., Int. Ed. 2007, 46, 3505-3508. doi:10.1002/anie.200604807

20. Kostyanovsky, R. G.; Gella, I. M.; Markov, V. I.; Samojlova, Z. E. Tetrahedron 1974, 30, 39-45. doi:10.1016/S0040-4020(01)97214-X

21. Campbell, M. M.; Johnson, G. Chem. Rev. 1978, 78, 65-79. doi:10.1021/cr60311a005

22. Lindsay-Smith, J. R.; McKeer, L. C.; Taylor, J. M. Org. Synth. 1989, 67, 222-228. doi:10.15227/orgsyn.067.0222

23. Larionov, O. V.; Kozhushkov, S. I.; de Meijere, A. Synthesis 2003, 1916-1919. doi:10.1055/s-2003-41037

24. Zhong, Y.-L.; Zhou, H.; Gauthier, D. R.; Lee, J.; Askin, D.; Dolling, U. H.; Volante, R. P. Tetrahedron Lett. 2005, 46, 1099-1101. doi:10.1016/j.tetlet.2004.12.088

25. Vanoye, L.; Yehouenou, L.; Philippe, R.; de Bellefon, C.; Fongarland, P.; Favre-Réguillon, A. React. Chem. Eng. 2018, 3, 188-194. doi:10.1039/C7RE00155J

26. Blacker, A. J.; Jolley, K. E. Beilstein J. Org. Chem. 2015, 11, 2408-2417. doi:10.3762/bjoc.11.262

27. Thakur, V. V.; Talluri, S. K.; Sudalai, A. Org. Lett. 2003, 5, 861-864. doi:10.1021/ol027530f

28. Sharpless, K. B.; Chong, A. O.; Oshima, K. J. Org. Chem. 1976, 41, 177-179. doi:10.1021/jo00863a052

29. Ando, T.; Kano, D.; Minakata, S.; Ryu, I.; Komatsu, M. Tetrahedron 1998, 54, 13485-13494. doi:10.1016/S0040-4020(98)00827-8

30. Chemler, S. R.; Bovino, M. T. ACS Catal. 2013, 3, 1076-1091. doi:10.1021/cs400138b

31. Göttlich, R. Synthesis 2000, 1561-1564. doi:10.1055/s-2000-7605

32. Noack, M.; Göttlich, R. Eur. J. Org. Chem. 2002, 3171-3178. doi:10.1002/1099-0690(200209)2002:18<3171::AID-EJOC3171>3.0.C $\mathrm{O} ; 2-\mathrm{L}$

33. Cadoni, R.; Porcheddu, A.; Giacomelli, G.; de Luca, L. Org. Lett. 2012, 14, 5014-5017. doi:10.1021/ol302175v

34. Porcheddu, A.; De Luca, L. Adv. Synth. Catal. 2012, 354, 2949-2953. doi:10.1002/adsc.201200659

35. Grogan, G.; Turner, N. J. Chem. - Eur. J. 2016, 22, 1900-1907. doi:10.1002/chem.201503954

36. Hussain, S.; Leipold, F.; Man, H.; Wells, E.; France, S. P.; Mullholland, K. R.; Grogan, G.; Turner, N. J. ChemCatChem 2015, 7, 579-583. doi:10.1002/cctc.201402797 
37. Wakchaure, V. N.; Kaib, P. S. J.; Leutzsch, M.; List, B. Angew. Chem., Int. Ed. 2015, 54, 11852-11856. doi:10.1002/anie.201504052

38. Spindler, F.; Blaser, H.-U. In The Handbook of Homogenous Hydrogenation; de Vries, J. G.; Elsevier, J., Eds.; Wiley-VCH, 2008; pp 1193-1214.

39. Blacker, A. J. In The Handbook of Homogenous Hydrogenation; de Vries, J. G.; Elsevier, C. J., Eds.; Wiley-VCH, 2008; pp 1215-1244.

40. Wills, M. In Topics in Current Chemistry; Guinella, G., Ed.; Springer International Publishing: Switzerland, 2016; Vol. 14, pp 1-36.

41. Bartsch, R. A.; Cho, B. R. J. Am. Chem. Soc. 1979, 101, 3587-3591. doi:10.1021/ja00507a025

42. Cho, B. R.; Namgoong, S. K.; Bartsch, R. A. J. Org. Chem. 1986, 51, 1320-1324. doi:10.1021/jo00358a030

43. Cho, B. R.; Namgoong, S. K.; Kim, T. R. J. Chem. Soc., Perkin Trans. 2 1987, 853-856. doi:10.1039/P29870000853

44. Zhu, R.; Xu, Z.; Ding, W.; Liu, S.; Shi, X.; Lu, X. Chin. J. Chem. 2014, 32, 1039-1048. doi:10.1002/cjoc.201400471

45. Liu, L.-W.; Wang, F.-Y.; Tian, F.; Peng, L.; Wang, L.-X. Org. Process Res. Dev. 2016, 20, 320-324. doi:10.1021/acs.oprd.5b00345

46. Scott, J. D.; Willams, R. M. Chem. Rev. 2002, 102, 1669-1730. doi:10.1021/cr010212u

47. Zhang, Y.; Feng, J.; Jia, Y.; Wang, X.; Zhang, L.; Liu, C.; Fang, H.; Xu, W. J. Med. Chem. 2011, 54, 2823-2838. doi:10.1021/jm101605z

48. Blacker, A. J.; Stirling, M. J.; Page, M. I. Org. Process Res. Dev. 2007, 11, 642-648. doi:10.1021/op060233w

\section{License and Terms}

This is an Open Access article under the terms of the Creative Commons Attribution License (http://creativecommons.org/licenses/by/4.0). Please note that the reuse, redistribution and reproduction in particular requires that the authors and source are credited.

The license is subject to the Beilstein Journal of Organic Chemistry terms and conditions:

(https://www.beilstein-journals.org/bjoc)

The definitive version of this article is the electronic one which can be found at: doi:10.3762/bjoc. 14.196 